Çukurova Üniversitesi Mühendislik Mimarlık Fakültesi Dergisi, 35(3), ss. 745-751, Eylül 2020

\title{
Merkezi Bir Isıtma Sisteminde Enerji ve Ekserji Analizinin Eksergoekonomik Yönden Değerlendirilmesi

\author{
İrfan UÇKAN ${ }^{* 1}$, Erkan ULUSOY ${ }^{2}$ \\ ${ }^{1}$ Van Yüzüncü Yıl Üniversitesi, Mühendislik Fakültesi, Makine Müh. Bölümü, Van \\ ${ }^{2}$ Van Yüzüncü Yıl Üniversitesi, Yapı işleri ve Teknik Daire Başkanlığı, Van
}

Geliş tarihi: 22.09 .2020

Kabul tarihi: 23.10 .2020

$\ddot{\mathbf{O z}}$

Bu çalışmada Van Yüzüncü Y1l Üniversitesi kampüsünde toplam 20 ton/saat buhar üreten merkezi 1sıtma sisteminin ekonomik ve Eksergoekonomik analizi yapılmıştır. Yapılan analiz sonucunda sistemin en önemli bölgesi olan kazanlardaki toplam enerji verimi ortalama olarak \%90, ekserji verimi ise \%31 olarak bulunmuştur. Tüm sistemin ekserjetik verimi ise \%29 olarak bulunmuştur. Eksergoekonomik analiz sonucunda sistemin yıllık yakıt tüketim bedeli, yıllık ürün maliyeti bedeli, sisteme giren ve çıkan parametrelerin birim ekserji maliyet bedelleri hesaplanmıştır. Hesaplar sonucunda ürünün saatlik maliyeti: 291,78 \$/h, yakıtın saatlik maliyeti: 252,30 \$/h, olarak bulunmuştur.

Anahtar Kelimeler: Enerji, Ekserji, Eksergoekonomik

\section{Exergoeconomic Evaluation of Energy and Exergy Analysis in a Central Heating System}

\begin{abstract}
In this study, the economical and exergoeconomik analysis of the central heating system which produces a total of 20 tons/hour of steam was conducted in in the Van Yüzüncü Y1l University campus. As a result of the analysis, the total energy efficiency of the boilers, which is the most important part of the system, was found to be $90 \%$ and the exergy efficiency as $31 \%$. The exergetic efficiency of the whole system was found to be $29 \%$. As a result of the exergoeconomic analysis, the annual fuel consumption cost of the system, the annual product cost price, the unit exergy cost of the parameters entering and leaving the system were calculated. As a result of the calculations, the hourly cost of the product was found to be: $291.78 \$ / \mathrm{h}$, the hourly cost of fuel: $252.30 \$ / \mathrm{h}$
\end{abstract}

Keywords: Energy, Exergy, Exergoeconomic

*Sorumlu Yazar (Corresponding author): İrfan UÇKAN, irfanuckan@yyu.edu.tr 


\section{GíRiş}

Dünya nüfusunun hızlı bir şekilde artmasıyla birlikte insanların sınırsız bir şekilde artan kişisel ihtiyaçları için, nüfusa paralel bir şekilde hızlıca artan ve artmaya devam eden sanayileşme, beraberinde çok ciddi enerji ihtiyaçları doğurmuştur. Rekabet, enerji ve üretim maliyetlerinin üretim alanında artması, üreticileri yüksek kaliteli ve standartlaştırılmış ürünleri düşük maliyetle sunmanın yollarını aramaya zorlamaktadır. Herhangi bir üretim organizasyonunun büyümesi ve hayatta kalması, ekonomisini ne kadar iyi yönetebileceğine bağlı olduğundan, maliyet yönetimi zorunlu hale gelmektedir [1].

Ancak, toplam kalite yönetim sistemi, hat rasyonalizasyonu, bütçe kontrolü, maliyet hacmi analizi, standart maliyet analizi ve süreç otomasyonu gibi mevcut maliyet yönetim teknikleri üretimle ilgili gizli maliyetleri belirlemek için yetersiz kalmaktadır [2]. Bu tekniklerin hiçbiri, üretim sürecinde kullanılan makinelerin, ekipmanın veya sürecin kendisinin tanımlanmasına odaklanmaz. Eğer bir sistem termodinamik sınırlar içerisinde enerji ekserji analizleri yapılmazsa büyük miktarda enerji ve yakıt tüketecektir ve daha sonra yüksek maliyet ve düşük verimlilikle çalışacaktır [3].

Eksergoekonomik analiz, bir makinenin, işlemin veya sistemin termodinamik sinırlamalarını ve bunun altında yatan maliyet etkilerini belirlemede yararlı bir araçtır. Sanayi proseslerindeki birçok sistemde enerji verimsiz kullanılmaktadır. Bu durum da yakıt masraflarının yükselmesine, ürün maliyetlerinin artmasına ve ülkelerin dışa bağımlı hale gelmesine sebep olmaktadır. Bu sebeple kurum ve kuruluşlar işletmelerinde enerji tasarrufu sağlamak adına enerji ve ekserji analizi ile birlikte eksergoekonomik analiz de yapmaya yönelmişlerdir.

Eksergoekonomik analizlerin genel amac1;

(i) Birden fazla ürüne sahip bir sistemde her ürün maliyetini ayrı ayrı hesaplamak,

(ii) Sistemin maliyet akışını ve şeklini anlamak, (iii) Sistemin temel elemanlarının spesifik değişkenlerini belirlemek ve bu değişkenleri optimize etmek,

(iv) Sistemi bir bütün olarak ele alıp optimizasyonunu yapmaktır [4].

Chejne ve Restrepo [5] çalışmalarında; çeşitlilik içeren üretim yöntemlerinin Eksergoekonomik metotlarına yeni bir bakış getirerek; sistemdeki kayıp enerji ve ekserjilerin birim maliyet kayıpları üzerinde çalışmışlardır. Üretimin verimi adına yapılmış olan bu çalışma eski ve yeni metotlarla kıyaslanmıştır.

Erlach ve arkadaşları [6] yapmış oldukları çalışma ile kojenerasyon sisteminde kullanılan yakıt tasarrufu ve maliyetin düşürülmesi için Eksergoekonomik analiz yapmışlar. Çalışmada ürün olarak buhar ve elektrik üretimi üzerinde durulmuştur. Ekserjetik maliyet yöntemi ile çalışmalarını yapmışlardır. Çalışma sonucunda bu yöntemin esnek bir analiz yöntemi olduğunu ve güç santrallerinde uygulanabilir olduğuna değinmişlerdir.

Sevilgen [7], gaz türbini ile çalışan kojenerasyonlu bir tesisin eksergoekonomik analizini yaparak rejeneratör verimi, atık 1sı kazanı sıcaklık farkı ve kompresör basıncının sistem üzerindeki etkilerini incelemiştir. Bu çalışmada yapılan iş ile buharın ekserjisinin toplam ekserji üzerine etkileri araştırılmıştır.

Seyyedi ve arkadaşları [8] çalışmalarında 1sıl güç tesislerinin eksergoekonomik analizlerini ekserji bozum maliyeti ve ilk yatırım maliyeti şeklinde bir yöntem kullanarak araştırmışlardır. Bu kullanılan yöntemin avantajı olarak, gerçek ve karmaşık görünen güç tesislerinde de uygulanabilir olduğunu ve detaylı sayısal analizler yapılabilmesi olarak özetlemişlerdir.

Termoekonomi birçok uygulamada mühendisliğin bir dalı olarak görülmektedir. Termoekonomi, ekonomik değerlendirmelerde enerji analizleri ile birlikte ekserji analizleri yapılarak sistemin verimini arttırmak ve sistemin ekonomik prensipleri de içermektedir [9]. 
Knoche ve Hesselmann, bir 1sı değiştirgecinin ilk yatırım maliyeti ile 1sı değiştirgecinde meydana gelen ekserji kaybı ilişkisi detaylandırılmıştır [10]. Zubair ve arkadaşları 1987, yaptıkları çalışmada bir termoekonomik sistem geliştirerek, çift akışlı 1sı değiştirgecinden geçen optimum 1sı geçiş birimi miktarını ikinci yasaya dayalı termodinamik çalışma yaparak bulmuşlardır [11].

Bu çalışmada Van Yüzüncü Yıl Üniversitesi kampüsü bir tek sistem olarak düşünülmüştür. Çalışmada kampüs 1sıtma sisteminin enerji ve ekserjisini etkileyen faktörlerin bulunup ortaya çıkarılması ve bu faktörlerin ekonomik analizlerinin belirlenmesi amaçlanmıştır.

\section{MATERYAL ve METOD}

Bu çalıșmada Van Yüzüncü Yıll Üniversitesinde merkezi 1sitma sisteminin farklı lokasyonlarda bulunan binaların 1sıtılması için kullanılan merkezi 1sıtma sisteminin eksergoekonomik analizi yapılmıştır. Çalışmada Van iklim şartları için altı aylık 1sitma sezonu verileri analiz edilmiştir. $\mathrm{Bu}$ değerlendirme yapılırken kazanlar, boru ağları ve eşanjör sistemleri gibi ana ekipmanların her biri için ayrı analizler yapılarak sistem dört ayrı bölgeye ayrılmıştır. Daha sonra alınan verilerden yararlanılarak sistemin eksergoekonomik yönden değerlendirilmesi yapılmıştır.

\subsection{Sistemin Tanıtılması}

Çalışılan sistemde enerji ve ekserji verimliliğini etkileyeceği düşünülen 4 önemli bölge mevcuttur.

1. bölge, buhar kazanları. $\mathrm{Bu}$ kazanlar tüm kampüsün buhar ihtiyacını karşılayan alev borulu, gaz yakıtla çalışan kazanlar olup; 6 bar ve 8 bar basınçta, saatte 8,5 ton ve 12 ton buhar üretebilmektedir. Kazanın giriş ve çıkış parametreleri Şekil 1'de gösterilmektedir. Kazan besi suyu sıcaklığı yaklaşık olarak $60-70 \quad{ }^{\circ} \mathrm{C}$ aralığında alınarak kazandan 2,5 bar basınçta ve $130{ }^{\circ} \mathrm{C}$ sicaklığında sisteme buhar verilmektedir. Bu buhar yaklaşık 8 km'lik galerilerde izolasyonlu siyah borular aracılığı ile fakülte ve idari binaların eşanjörlerinde primer devre kısmını tamamlamaktadir.

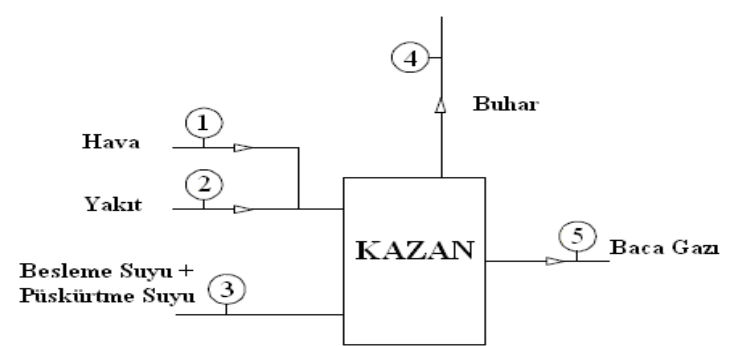

Şekil 1. Sistemde kullanılan sürekli açık, sürekli akışlı buhar kazanına giren ve çıkan elemanlar

2. bölge, boru ağlarından oluşmaktadır. Sistemde ortalama $8 \mathrm{~km}$ 'lik galeri ağları mevcut olup bu galerilerde buhar ve yoğuşum hatları dolaşmaktadır. $\mathrm{Bu}$ borular çeşitli yoğuşum hatları ile taşınmış olup; taş yünü ve galvaniz sac izolasyonları ile enerji kaybının azaltılması sağlanmıştır.

3. bölge, eşanjörler. Sistemde toplam 49 adet eşanjör dairesi mevcut olup buralarda kullanılan 1sı değiştirgeçleri buhar eşanjörleridir. Eşanjörlerde eşanjör ceketi ve çeşitli kimyasallar ile kireçlenmenin önüne geçilerek verimin arttırılması istenmiştir.

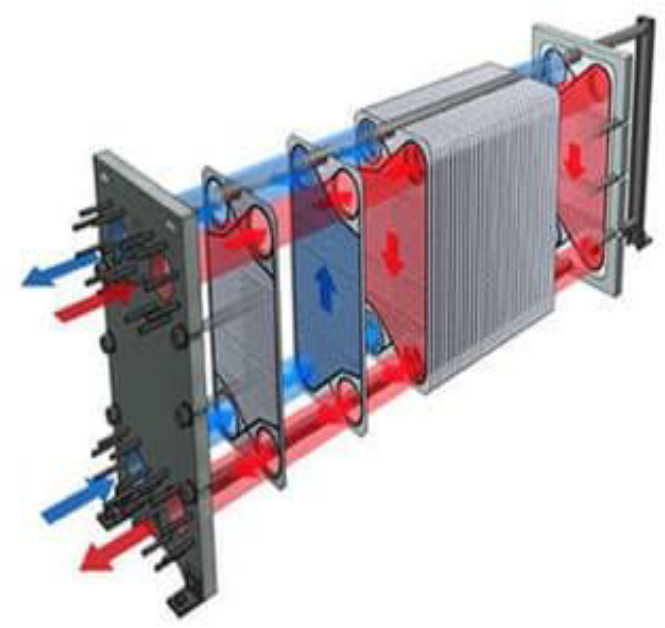

Şekil 2. Plakalı buhar eşanjörü [12]

4. bölge ise elektrik motorları. Bu motorlar brülör, taze hava fan motorları ve yoğuşum pompalarından oluşmaktadır. 


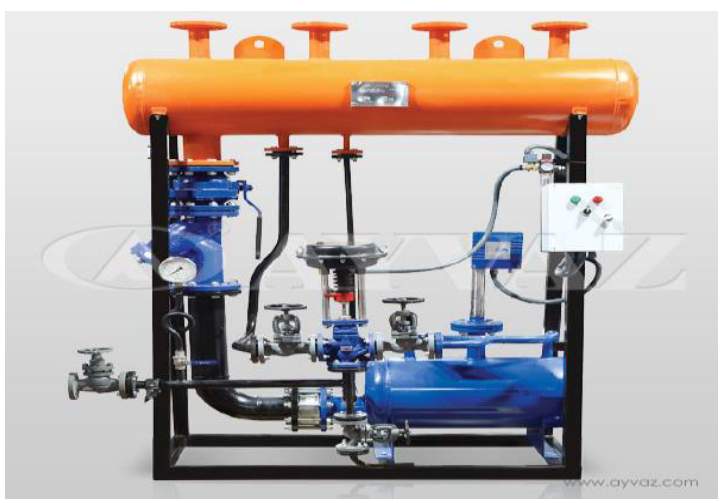

Şekil 3. Kondens Pompası şeması [13]

\subsection{Sistemin Ekonomik Analizi}

$\mathrm{Bu}$ çalışma, 1sıtma sisteminin faal olduğu altı aylık süre içerisinde değerlendirilmiştir. $\mathrm{Bu}$ süre içerisinde $3.759 .028 \mathrm{~m}^{3}$ yakıt (Doğalgaz) kullanılmıştır.

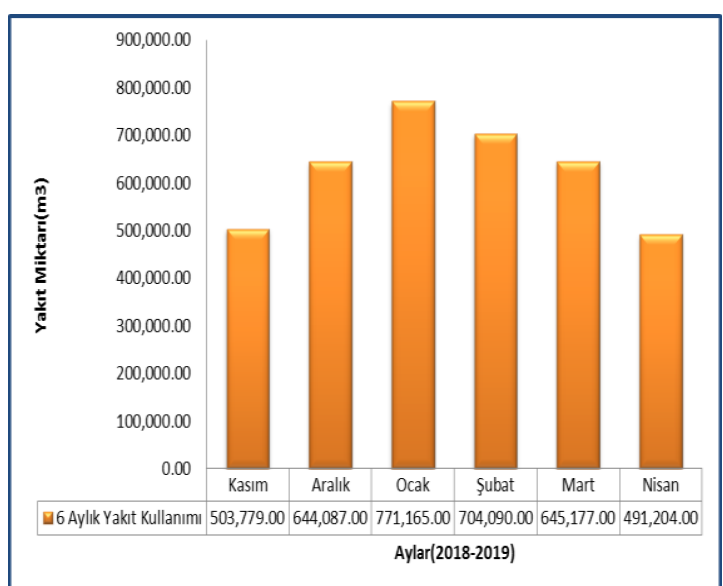

Şekil 4. Isıtma sezonundaki aylık yakıt tüketimi

Van Yüzüncü Yıl Üniversitesi 1sitma sistemi Kasım 2018-Nisan 2019 arasinda 180 gün çalışmışırı. Mevcut zaman aralığında yakıt tüketiminin en fazla olduğu ay yaklaşık olarak $772.000 \mathrm{~m}^{3}$ değeri ile Ocak ayında görülmüştür. Ocak ayında yakıt tüketimin diğer aylara göre fazla olmasının en önemli nedeninin bu aydaki dış ortam sıcaklığının diğer aylara göre düşük olmasindan kaynaklanmaktadır. Dolayisıyla bu aydaki binaların 1S1 kaybının da fazla olması nedeniyle yakıt tüketimi diğer aylara göre daha fazla ölçülmüștür. Ancak Nisan ve Kasım aylarında tüketilen yakıt miktarı yaklaşık olarak $500.000 \mathrm{~m}^{3}$ değeri ile birbirlerine yakın çıkmıştır (Eşitlik 1-4).

$\dot{\mathrm{C}}_{\text {ürün }}=\dot{\mathrm{C}}_{\text {yakıt }}+\dot{\mathrm{Z}}_{\text {ilkyat.oranı }}$

$\dot{\mathrm{Z}}_{\text {ikyat.oranı }}=\frac{\mathrm{a}}{\mathrm{t}_{\mathrm{op}}} \mathrm{C}_{\mathrm{k}}$

$\dot{\mathrm{C}}_{\text {ürün }}=$ Ürünün maliyeti

$\dot{\mathrm{C}}_{\text {yaktt }}=$ Yakıt maliyeti

$\dot{\mathrm{Z}}_{\text {ilkyat.oranı }}=$ Yatırım maliyet oranı

$a=\frac{f_{r}\left(1+f_{r}\right)^{N}}{\left(1+f_{r}\right)^{N}-1}$

$\mathrm{a}=$ Yatırım dönüșüm oranı

$\mathrm{f}_{\mathrm{r}}=$ Faiz oran

$\mathrm{N}=$ Ödeme periyodu

$\mathrm{C}_{\mathrm{k}}=$ Proses toplam maliyeti

$\mathrm{t}_{\mathrm{op}}=$ Kazanın yıllık çalışma saati $=4320$ saat

$\mathrm{C}_{\mathrm{k}}=\mathrm{C}_{\text {sis }}+\mathrm{Z}_{\mathrm{m}} \$$

$\mathrm{C}_{\mathrm{sis}}=$ Sistemin ilk yatırım maliyeti

$\mathrm{Z}_{\mathrm{m}}=$ Bakım onarım maliyetleri

$\mathrm{C}_{\mathrm{y}}=$ Bakım onarım gerektiren elemanın yat. mal.

$Z_{\mathrm{m}}=Z_{\mathrm{b}}+Z_{\mathrm{s}}+Z_{\mathrm{f}}$

$\mathrm{Z}_{\mathrm{b}}=0,13 \frac{\mathrm{C}_{\mathrm{y}}}{\mathrm{N}}$ (bakım onarım giderleri)

$Z_{s}=0,53 \frac{C_{y}}{N}$ ( yedek parça giderleri)

$\mathrm{Z}_{\mathrm{f}}=0,02 \frac{\mathrm{C}_{\mathrm{y}}}{\mathrm{N}}$ (nakil montaj giderleri)

$\dot{\mathrm{Z}}_{\text {ilk yat.oranı }}=\frac{\mathrm{a}}{\mathrm{t}_{\mathrm{op}}} \mathrm{C}_{\mathrm{k}}$

\subsection{Sistemin Eksergoekonomik Analizi}

Sistem için ekserji maliyet dengesi (Eşitlik 5);

$\sum \dot{\mathrm{C}}_{\mathrm{g}}+\dot{\mathrm{Z}}=\sum \dot{\mathrm{C}}_{\mathrm{c}}$ 
Ekserji maliyeti (Eşitlik 6-7);

$\dot{\mathrm{C}}_{\mathrm{x}}=\mathrm{c}_{\mathrm{x}} \dot{\mathrm{E}}_{\mathrm{xx}}$

$\dot{\mathrm{C}}_{\mathrm{x}}=\left(\frac{\$}{\mathrm{~h}}\right)$

$\dot{\mathrm{C}}_{\mathrm{x}}=\left(\frac{\$}{\mathrm{~h}}\right)$ cinsinden ekserji akışlarının maliyet akımlarını göstermektedir.

$\mathrm{c}_{\mathrm{x}}=\left(\frac{\$}{\mathrm{~kJ}}\right)$ cinsinden ekserji akışlarının birim maliyetlerini göstermektedir.

Yakma havası sisteme vantilatör ile sağlanmaktadır. Yakma havası için birim ekserji maliyeti aşağıda verilen Eşitlik 9 ile ifade edilebilir.

$\mathrm{c}_{1}=\frac{\dot{\mathrm{C}}_{1}}{\dot{\mathrm{E}}_{\mathrm{X} 1}}$

Yakıt için birim ekserji maliyeti (Eşitlik 10):

$\mathrm{c}_{2}=\frac{\dot{\mathrm{C}}_{2}}{\dot{\mathrm{E}}_{\mathrm{X} 2}}$

Besleme suyu için birim ekserji maliyeti (Eşitlik 11):

$\mathrm{c}_{3}=\frac{\dot{\mathrm{C}}_{3}}{\dot{\mathrm{E}}_{\mathrm{X} 3}}$

Buhar için birim ekserji maliyeti (Eşitlik 12):

$\mathrm{c}_{3}=\mathrm{c}_{4}$

Buhar kazanına, yakıt, besleme suyu ve yakma havası giren akım, buhar ve baca gazı çıkan akımlardır. Buna göre, buhar kazanı için baca gazı birim ekserji maliyeti denklemi aşağıdaki eşitlik ile elde edilir (Eşitlik 13).

$\mathrm{c}_{1} \dot{\mathrm{E}}_{\mathrm{x} 1}+\mathrm{c}_{2} \dot{\mathrm{E}}_{\mathrm{x} 2}+\mathrm{c}_{3} \dot{\mathrm{E}}_{\mathrm{x} 3}+\dot{\mathrm{Z}}=\mathrm{c}_{4} \dot{\mathrm{E}}_{\mathrm{x} 4}+\mathrm{c}_{5} \dot{\mathrm{E}}_{\mathrm{x} 5}$

Sistemin kayıp ekserji (tersinmezlik) maliyeti (Eşitlik 14):

$\dot{\mathrm{C}}_{\text {kayıp }}=\mathrm{c}_{\mathrm{y}} \dot{\mathrm{E}}_{\mathrm{xkay} ı \mathrm{p}}$
Maliyet Farkı Oranı (Eşitlik 15):

$\mathrm{r}_{\mathrm{k}}=\frac{\dot{\mathrm{C}}_{\text {ürün}}-\dot{\mathrm{C}}_{\text {yakıt }}}{\dot{\mathrm{C}}_{\text {yakıt }}}$

Eksergoekonomik faktör: Bir sistemin yatırım maliyeti ile karşılaştırıldığında gizli maliyetin etkisinin bir ölçüsüdür. Herhangi bir sistemin eksergoekonomik faktörü şu şekilde hesaplanabilir [14] (Eşitlik 16 ve 17).

$\mathrm{f}=\frac{\dot{\mathrm{Z}}_{\text {sis }}}{\grave{\mathrm{Z}}_{\text {sis }}+\dot{\mathrm{C}}_{\text {kayp }}}$

Ekserjetik Verim:

$\mu=1-\frac{\dot{E}_{\text {Xkayip }}}{\dot{\mathrm{E}}_{\text {Xyaktt }}}$

\section{BULGULAR}

Şekil 5'te görüleceği üzere kazana giren ve kazandan çıkan akışların saatlik maliyetleri $\$ / \mathrm{h}$ cinsinden değerlendirildiğinde en düşük akış maliyetinin $4,44 \$ / \mathrm{h}$ ile yakma havası maliyetleri olduğu, en büyük maliyetin ise 278,68 \$/h ile baca gazı maliyeti olduğu görülmektedir. Bunun sebebi ise bacalardaki ekserjinin fazla olmasidır. Baca gazı sıcaklığının fazla olması ve yakıt maliyetinin optimum seviyelere çekilememesidir.

yakma havası $\square$ yakit $\square$ besi suyu $\square$ buhar $\square$ baca

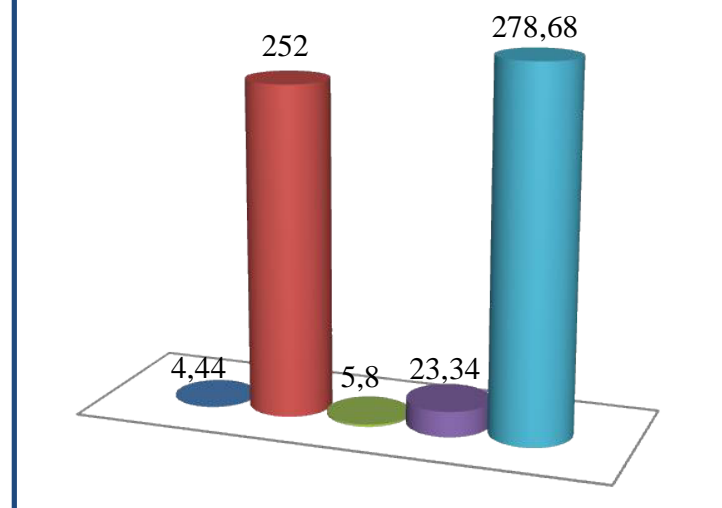

Şekil 5. Sistemi oluşturan akımların maliyet tablosu $(\$ / \mathrm{h})$ 
Şekil 6'da kazanda meydana gelen akımların birim ekserji maliyetleri görülmektedir. Birim ekserji, akımın yakıt maliyetinin, akımın ekserjisine oranı ile belirlenmektedir. Burada da görüleceği üzere yakma havası birim ekserji maliyeti $8 \times 10^{-6} \$ / \mathrm{kj}$, yakıtın birim ekserji maliyeti $4 \times 10^{-6} \$ / \mathrm{kj}$, besi suyu birim ekserji maliyeti $1 \times 10^{-6} \$ / \mathrm{kj}$, buharın birim ekserji maliyeti $1 \times 10^{-6} \$ / \mathrm{kj}$ ve baca gazı birim ekserji maliyeti ise $45 \times 10^{-6} \quad \$ / \mathrm{kj}$ olduğu görülmektedir. Burada en büyük maliyetin baca gazı maliyeti, en düşük birim maliyetin ise besi suyu ve buhar maliyetleri olduğu görülmüştür.

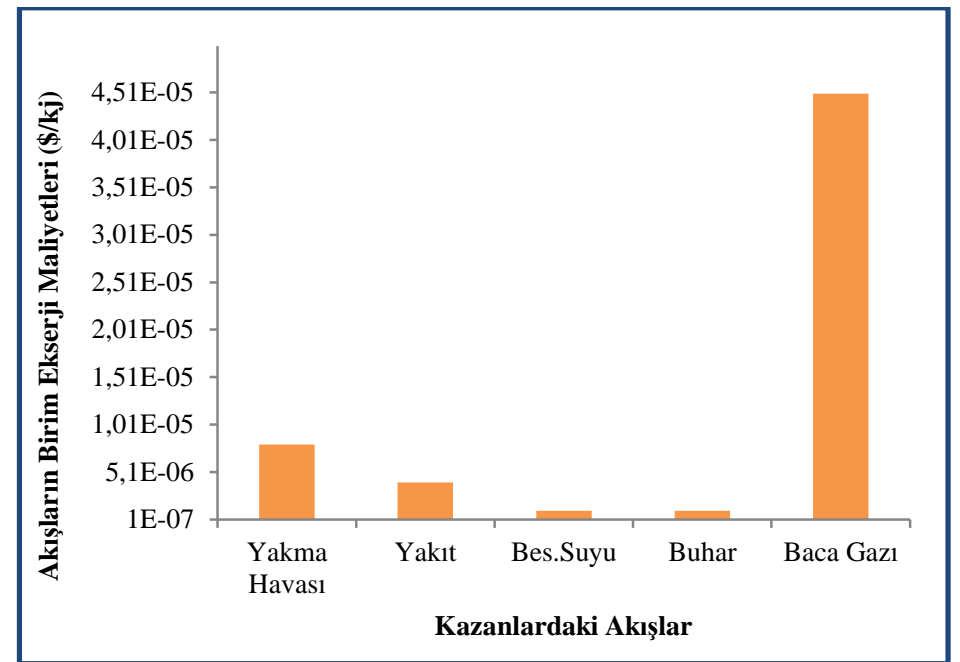

Şekil 6. Sistemi oluşturan akımların birim ekserji maliyet tablosu $(\$ / \mathrm{h})$

Şekil 7'de ürün maliyetinin yakıt maliyeti ile doğrudan ilgisi olduğu görülmektedir. Maliyetler $\$ / h$ cinsinden verilmiştir. Ürün maliyeti, yakıt maliyeti ve ilk yatırım maliyetinin toplamıla oluşmaktadır. Yakıt maliyeti ise yakıtın cinsine ve çalışma şartlarına göre farklılık göstermektedir. Maliyet farkı oranı ise ürün maliyeti ile yakıt maliyetinin oranı sonucunda ortaya çıkmaktadır.

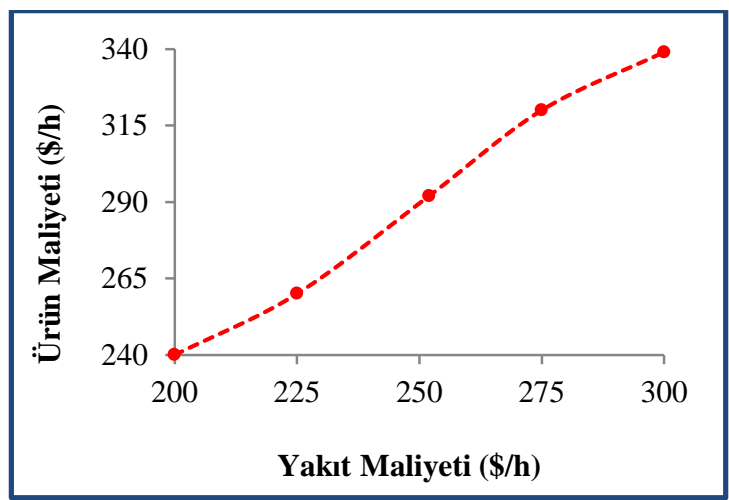

Şekil 7. Ürün maliyetinin yakıt maliyeti ile değişimi

\section{SONUÇ}

Sistem bir bütün olarak ele alındığında, sistemin en önemli elemanı olan kazanlardaki toplam enerji verimi ortalama olarak \%90, ekserji verimi ise \%31 olarak bulunmuştur. Tüm sistemin ekserjetik verimi ise \%29 olarak bulunmuştur. Sistemdeki ekserji kayıplarının yaklaşık olarak \%95'i kazanlarda olmaktadır. \%2,8'i boru hatlarında, \%1,6'sı eşanjörlerde gerçekleşmektedir. Bunların temel sebepleri; baca gazı 1sısı ile doğaya bırakılan enerjinin fazlalığı, hava fazlalık katsayısının optimum düzeyde tutulamaması ve besi suyu sıcaklığının istenen seviyede olmamasıdır.

Tüm açıklanan sebeplerle sistemin verimini ve buna bağlı olarak ekonomik iyileşmesini daha iyi bir hale getirmek için aşağıdaki maddelerin uygulanması gerekmektedir.

- Kazanlarda, yakma havası sıcaklığının ekserji verimine etkisini arttırmak için ön 1sıtıcı kullanılması gerekmektedir. 
- Kazanlarda yanma sirasında yakıt/hava karışımının doğru ayarlanması gerekmektedir. Aksi taktirde tam yanma olmayacağı için verimde olumsuz etkiler görülecektir. Bu sebeple hassas elektronik algılama cihazları kullanılmalı ve sürekli bakımları yapılmalıdır.

- Baca gazlarının isılarından daha fazla faydalanılabilinmesi için ekonomizerlerin sağlıklı bir şekilde takip edilmesi ve bakımlarının yapılması gerekmektedir.

\section{KAYNAKLAR}

1 Ben-Caleb, E., Otekunrin, A., Rasak, B., Adewara, S., Oladipo, O., Eshua R. 2019. Cost Reduction Strategies and the Growth of Selected Manufacturing Companies in Nigeria, Int. J. Mech. Eng. Technol. 10, 305-312.

2 Sailaja, A., Basak, P., Viswanadhan, K. 2015. Costs of Quality: Exploratory Analysis of Hidden Elements and Prioritization Using Analytic Hierarchy Process, Int. J. Supply Oper. Manag. 1, 489-506.

3 Ghannadzadeh, A., 2013. Exergetic Balances and Analysis in a Process Simulator: a Way to Enhance Process Energy Integration.

4. Tsatsaronis, G., Moran, M., 1997. ExergyAided Cost Minimization” Energy Conversation Management, 38(15-17), 1535-1542.

5. Chejne, F., Restrepo, J.A., 2003. New Rules for the Exergo-economic Optimization Methodology, Energy, 28, 993-1003.

6. Erlach, B., Tsatsaronis, G., Cziesla, F., 2001. A New Approach for Assigning Costs and Fuels to Cogeneration Products, In. J. Applied Thermodynamics, 4(3), 145-156.

7. Sevilgen, S.H., 2004. Exergoeconomic Analysis of Cogeneration System, Journal of Engineering and Natural Sciences, 4, 234-248.

8. Seyyedi, S.M., Ajam, H., Farahat, S., 2010. A New Approach for Optimization of Thermal Power Plant Based on the Exergoeconomic Analysis and 751 Tructural Optimization Method: Application to the CGAM Problem, Energy Conversion and Management, 51(11), 2202-2211.
9. Bejan, A., Tsatsaronis, G., Moran, M., 1996. Thermal Desing and Optimizasyon. A WileyInterscience Publcation, John Wiley\&Sons, Inc., New York.

10. Knoche, K.F., Hesselmann, K., 1985. Exergoökonomische Bewertung Einer Luftzerlegungs Anlage, Chem.-Ing. Tech. 57, 602-609.

11.Zubair, S.M., Kadaba, P.V., Evans, R.B., 1987. Second-Law Based Thermoeconomic Optimization of two-phase Heat exchangers, Journal Heat Transfer, 109, 287-294.

12. Alfa lawal. https://www.alfalaval.com.tr/

13. Ayvaz Vana https://www.ayvaz.com/

14. G. Tsatsaronis. 2011. Exergoeconomics and Exergo Environmental Analysis, in: B.R. Bakshi, T.G., Gutowski, D.P., Sekulic (Eds.), Thermodynamics and the Destruction of Resources, Cambridge University Press, USA, 377-388. 
